occupation stated at interview were used as an indicator of occupational exposure. Odds ratios (OR) and 95\% confidence intervals $(\mathrm{CI})$ were estimated using unconditional logistic regression and attributable fraction (AF) by Miettinen's formula, adjusted for smoking pack years, HIV status and domestic fuel type use. Results The mean age of cases and controls was 56.0 and 57.1. Among men, adjusted OR for lung cancer was 3.0 (95\% CI 1.46.4) in miners and 1.7 (95\% CI 1.3-3.2) in transport occupations. In women, the adjusted OR in domestic workers was 7.3 (95\% CI 1.7-11.3) whereas working in the food and beverage industry was 4.9 (95\% CI 1.4-26.8). Occupation resulted in an $\mathrm{AF}$ of $14 \%$ in men and $26 \%$ in women.

Conclusions Occupational risk factors for lung cancer in South Africa are gender-specific, having more impact in women than in men. Further studies are needed to assess possible specific exposures in the mining and transport industries for men, and food industry and private homes for women.

\section{MESOTHELIOMA RATES IN SOUTH AFRICA: TRENDS 1995-2008}

${ }^{1,2}$ Cornelius Nattey, ${ }^{2}$ Danuta Kielkowski. ${ }^{1}$ National Institute for Occupational Health, National Health Laboratory Services, Johanneburg, Gauteng, South Africa; ${ }^{2}$ National Cancer Registry, National Health Laboratory Services, Johanneburg, Gauteng, South Africa

\subsection{6/oemed-2014-102362.349}

Objectives Mesothelioma is a rare neoplasm which is caused by asbestos exposure. South Africa has mined and refined all three types of asbestos since 19th century with the peak of production in1940-1980s. At present asbestos use and production is banned in South Africa. Trend 1995-2008 in mesothelioma rate was assessed to determine burden of asbestos related deaths due to mesothelioma by year and gender.

Method Death certificates with underlying cause of death stated as C45 were selected for the study in 1995-2008. For each year of study, age and gender distribution was obtained from the national statistical releases. Mesothelioma rates, 95\% confidence interval were calculated for each year and sex, and for age groups and sex. Poisson regression was used to test for trend.

Results In total 2497 cases were identified of deaths due to mesothelioma, 1919 in men and 578 in women in the study period. There was 3:1 male to female ratio. The trend was stable and constant over time for both men and women cases. Mortality rate in men was $8-16$ per million and in women $2-5$ per million.

Conclusions If mortality rate remains at current estimates we can expect 2134 cases until 2020. However, it is authors opinion that mortality rate is underestimated due to the competing causes of death, and shortened longevity. Just looking at other countries and their diagnosed cases, such as Great Britain, major consumer of asbestos from South Africa, it becomes apparent how little mesothelioma cases are diagnosed in our country.

\section{OCCUPATIONAL ACCIDENTS AND DISEASES AMONG COMMUNITY HEALTH AGENTS IN THE MUNICIPALITY OF CARAGUATATUBA/SP}

${ }^{1}$ Patricia Baptista, ${ }^{2}$ Mirian Almeida, ${ }^{2}$ Arlete Silva. ${ }^{1}$ University of Sao Paulo, Sao Paulo, Brazil; ${ }^{2}$ University of Guarulhos, Guarulhos, Sao Paulo, Brazil

10.1136/oemed-2014-102362.350
Objectives Identify and analyse of the occupational accidents and diseases occurred with the community health agents in the municipality of Caraguatatuba/SP.

Method This descriptive, exploratory, cross-sectional field study with a quantitative approach had the purposes of identifying and analysing of the occupational accidents and diseases occurred with the community health agents in the municipality of Caraguatatuba/SP. The data were collected from 137 workers by means of a questionnaire and an interview.

Results The data related to occupational accidents reveal that less than half $(59 ; 43.07 \%)$ of the workers had occupational accidents, most of them $(44 ; 74.59 \%)$ having reported one; the total of accidents reported was 80 , and the most frequent were biker trauma in traffic accidents $(43 ; 53.75 \%)$, followed by dog bites $(13 ; 16.25 \%)$ and falls $(12 ; 15.00 \%)$; the most frequent type of occupational accident was the typical $(64 ; 80.00 \%)$, followed by road accidents $(13 ; 16.25 \%)$ and occupational disease (3; 3.75\%). Besides, $22.63 \%$ reported diseases as osteomuscular system and of the connective tissue $(13 ; 30.96 \%)$, diseases of the circulatory system $(7 ; 16.68 \%)$, the respiratory system, mental and behavioural disorders, skin and subcutaneous tissue diseases (4; 9.52\%, respectively).

Conclusions The data point to the importance for an investment in the health community health agents in the municipality of Caraguatatuba/SP with training program.

\section{PATIENTS' VIEWS AND EXPECTATIONS ON SOCIAL WORK SERVICES IN THE OCCUPATIONAL MEDICINE CLINIC IN THE MACCABI HEALTH SERVICE ORGANISATION}

1,2 2 hhlomo Moshe, ${ }^{3}$ Tali Tzinamon, ${ }^{2,4}$ Gabriel Chodick, ${ }^{1,2}$ Oren Zack, ${ }^{1,3}$ Marla Tal. ${ }^{1}$ Maccabi Healthcare Services, Holon, Israel; ${ }^{2}$ The Public Health School, Sackler Faculty of Medicine, Tel-Aviv, Israel; ${ }^{3}$ Maccabi Healthcare Services, Social Services, Tel-Aviv, Israel; ${ }^{4}$ Maccabi Healthcare Services, Central Headquarter, Tel-Aviv, Israel

10.1136/oemed-2014-102362.351

Objectives To explore patients' expectations regarding the social work service and to deterrmine their satisfaction level with the care provided to them so far by the social worker in the framework of the occupational clinic.

Method This is a cross-sectional study which consists of Maccabi members of working age that visited occupational nedicine departments between September 2011 and July 2012 for the purpose of fitness-for-work evaluation who were referred to and met with a social worker. These members filled out an expectation and satisfaction questionnaire after meeting with the social worker.

Results A total of 203 questionnaire were filled out. Most of the patients were interested in receiving information about their benefits (85\%). A smaller number of patients (39.2\%) were interested in receiving help dealing with a family members' distress due to the loss of work ability of the patient. A very high percentage of the patients (97\%) were satisfied with the social worker session. A correlation was found between the patients' expectations and their satisfaction with the amount of information they received $(\mathrm{p}>0.01)$.

Conclusions This is a first study of this kind addressing social work services in a public occupational medicine services. The study shows the positive advantage of this service and a high patient satisfaction level with the social work service. The satisfaction level was high even though the patients' health status 